\title{
O CELULAR OU A VIDA: A CASA ABRIGO SOB A ÓTICA DE MULHERES EM SITUAÇ̃̃O DE VIOLÊNCIA
}

CELLPHONE OR LIFE: THE SHELTER FROM THE PERSPECTIVE OF WOMEN IN SITUATIONS OF VIOLENCE

\section{RESUMO}

O presente estudo busca analisar o funcionamento da Casa-Abrigo Municipal de Campina Grande - CAMCG, sob a ótica das mulheres em situação de violência abrigadas, em atendimento, e egressas da unidade. $\mathrm{O}$ estudo utilizou a abordagem qualitativa e os instrumentos para coleta de dados foram a pesquisa documental e entrevistas semiestruturadas com mulheres abrigadas e egressas. Os resultados evidenciaram a presença de todos os tipos de violência e a vergonha, o medo e a humilhação são sentimentos que constam em quase todos os relatos. O trabalho desenvolvido pela casa-abrigo garante segurança e proteção a vidas das mulheres abrigadas, em contrapartida, os relatos identificam um questionamento no sentido do abrigamento ser entendido como prisão e, assim, representar para as abrigadas uma inversão injusta entre agressor-agredida.

Palavras-chave: Violência contra a mulher. Políticas públicas. Casas-abrigo.

\begin{abstract}
The present study seeks to analyze the operation of the Campina Grande Municipal Shelter - CAMCG, from the point of view of women in situations of violence sheltered, in care, and out of the unit. The study used the qualitative approach and the instruments for data collection were documentary research and semi-structured interviews with sheltered and outgoing. The results evidenced the presence of all types of violence and shame, fear and humiliation are feelings that are found in almost all the stories. The work carried out by the shelter ensures safety and protection of sheltered women's lives, in contrast, the reports identify a questioning in the sense that shelter is understood as imprisonment and, thus, represent for the sheltered an unfair inversion between aggressor-assaulted.
\end{abstract}

Keywords: Violence against women. Public policy. Shelter houses.

Isabella A. M. Chaves

Universidade Federal da Paraíba. E-mail: bella.amr@gmail.com

Loreley G. Garcia

Universidade Federal da Paraíba. E-mail: loreleygg@gmail.com 


\section{Introdução}

A presente pesquisa se propõe a analisar o funcionamento das casas-abrigo no município de Campina Grande, na Paraíba, sob a ótica das mulheres em situação de violência abrigadas e egressas das unidades, contribuindo com algumas reflexões sobre a política de abrigamento aplicadas no estado.

Para isso, é importante compreender a violência contra a mulher como fenômeno histórico e socialmente construído, sob o aspecto de um problema social, jurídico, cultural e de saúde pública, considerando todas as peculiaridades envolvidas no contexto no qual ocorrem os episódios violentos.

Por entender a violência como preocupação mundial, a Organização Mundial de Saúde - OMS (2002), em seu Relatório mundial sobre violência e saúde, conceitua a violência como a ameaça ou prática, por meio da força física ou uso de poder, de maneira intencional, contra uma pessoa, grupo ou instituição que tenha como resultado o sofrimento, privação ou dano psicológico, desenvolvimento prejudicado ou morte.

Dos diferentes tipos de violência existentes, esse estudo abordará a violência doméstica e familiar contra a mulher, uma vez que é assim tratada pela legislação vigente, pelos mais recentes estudos sobre a temática, bem como pelas medidas e serviços oferecidos pelos órgãos que compõem a rede de atendimento às mulheres em situação de violência.

A violência contra as mulheres constitui um fenômeno de natureza complexa, haja vista as relações sociais e afetivas nela envolvidas. Trata-se de um fenômeno recorrente nas sociedades atuais e que pode ser verificada em vários países.

A década de 1980 inaugura no Brasil um novo panorama na perspectiva do reconhecimento da violência contra a mulher. Fruto das lutas feministas, as quais começavam a ganhar força no país, os primeiros passos para o enfrentamento à violência contra a mulher são iniciados, como a criação das Delegacias para Mulher e o primeiro serviço de atendimento à mulher em situação de violência, o SOS Mulher, conforme ressaltado por Gregori (1993, p. 25-67).

Nesse contexto, conforme dispõem Bandeira e Almeida (2015, p. 502), a década seguinte é marcada por importantes convenções internacionais envolvendo a temática da violência contra a mulher, merecendo destaque a Conferência Mundial sobre Direitos Humanos, promovida pela Organização das Nações Unidas (ONU), ocorrida em Viena, em 1993 e a Convenção Interamericana para Prevenir, Punir e Erradicar a Violência contra a Mulher, conhecida como Convenção de Belém do Pará, realizada nesta cidade, em 1994.

O principal marco legal a respeito da violência contra mulher, no Brasil, foi a criação da Lei no. 11.340/o6, conhecida como Lei Maria da Penha, a qual garante o cumprimento das convenções internacionais de direitos humanos, reconhecida pela ONU como uma das melhores legislações do mundo em nível de violência. A Lei Maria da Penha visa coibir a violência doméstica e familiar contra a mulher, 
estabelecendo medidas assistenciais, de prevenção e de proteção às mulheres em situação de violência. Através de suas medidas protetivas de urgência, a mulher em situação de violência pode ser encaminhada com prioridade ao serviço adequado para sanar qualquer violência atual ou iminente.

Dentre as medidas protetivas as quais se refere a Lei Maria da Penha está a criação das Casas-Abrigo, expressa em seu artigo 35, II, que prevê a possibilidade de criação das unidades para mulheres e seus filhos menores, cuja iniciativa pode partir da União, Estados e Distrito Federal e Municípios.

Segundo as Diretrizes Nacionais para o Abrigamento de Mulheres em Situação de Violência, da Secretaria de Políticas para Mulheres (SPM), as casas-abrigo são locais seguros que oferecem moradia protegida e atendimento integral a mulheres em risco de vida iminente em razão da violência doméstica, tratando-se de um serviço de caráter sigiloso e temporário, no qual as usuárias permanecem por um período determinado, durante o qual deverão reunir condições necessárias para retomar o curso de suas vidas.

O local deve contar com uma equipe de profissionais de vários setores que promovem o acolhimento e assistência às mulheres, além da criação de estratégias para enfrentar o problema da violência.

As Casas-Abrigo devem assumir o compromisso de garantir a estada de mulheres, e seus filhos, que tenham vivenciado situação de violência no âmbito familiar, que estejam em risco de vida ou grave ameaça, de maneira segura e sigilosa, como bem explicam Carneiro e Oliveira (2008, p. 2).

Embora alguns questionamentos sejam feitos acerca da política deabrigamento, Silveira (2006, p. 66), por sua vez, defende que a situação de abrigo para os casos de risco de vida é uma contingência que se impõe a todo serviço de atendimento direto a mulheres em situação de violência e, muitas vezes, a única alternativa possível tem sido a retirada da mulher da sua moradia, juntamente com seus filhos.

Amorim e Barros (2014, p.14) ressaltam o caráter excepcional do abrigamento de mulheres em situação de violência, no qual o encaminhamento para a unidade deverá ser a última medida, após esgotar as possibilidades de manutenção das vítimas em seu convívio familiar com segurança e proteção.

As casas-abrigo se apresentam como um importante meio de garantir a segurança das mulheres em situação de violência doméstica e familiar, afastando o risco de morte enquanto as medidas judiciais cabíveis são aplicadas para punição de seus agressores, entretanto, o abrigamento jamais pode significar a injustiça e o aprisionamento de quem sofre a violência e sim, um local seguro e um instrumento de recomeço e ressocialização de quem carrega o sofrimento no corpo e na alma.

No estado da Paraíba, a política de abrigamento se concentra em duas casasabrigos em funcionamento, uma na cidade de João Pessoa/PB, a Casa-Abrigo Aryane Thaís e outra na cidade de Campina Grande/PB, a Casa-Abrigo Municipal de Campina Grande (Casa da Mulher). Essa última se apresenta como objeto de estudo e o campo da presente pesquisa. 
A Casa-Abrigo Casa da Mulher, localizada na cidade de Campina Grande/PB é uma unidade municipal, administrada pela Prefeitura deste município e obedece às Diretrizes Nacionais para o Abrigamento, documento o qual faz parte do programa de Política Nacional de Abrigamento.

É válida a ressalva de que as casas-abrigo não foram criadas a partir da Lei Maria da Penha. De fato, no Brasil, conforme pesquisa realizada pela Secretaria de Políticas para as Mulheres (SPM), no ano de 2009, a primeira casa-abrigo foi criada ainda na década de 80 , mais precisamente no ano de 1983, chamada de Casa da Mamãe, localizada na cidade de São Paulo/SP, inicialmente com a finalidade de abrigar mulheres e seus filhos em situação de abandono, em 1999, passou por uma reestruturação para acolher mulheres em situação de violência. Em 1986, foi instituída o COMVIDA (Centro de Convivência para Mulheres Vítimas de Violência), uma casa-abrigo objetivando o atendimento de mulheres em situação de violência), também em São Paulo, mas foi desativada após três anos de funcionamento.

A Lei Maria da Penha promove um resgate dessa política pública de enfrentamento à violência contra a mulher, tornando-a parte integrante da rede de combate e assistência a este tipo de violência.

\section{Violência contra a mulher e políticas públicas}

Dentro do campo da sociologia, a teoria clássica traz a análise da violência, enquanto fenômeno social, relacionando sua definição com os conceitos de controle social e do papel do Estado, este considerado como órgão central de controle, que exerce legitimamente a violência para manutenção da ordem social.

Nacionalmente, diversas pesquisas no campo das ciências sociais cuidaram de analisar a violência institucional, entendida como aquela praticada pelo Estado, assim como os vastos estudos sobre o período militar e, mais recentemente, o sistema de justiça criminal e penitenciário brasileiro.

Confirmando este posicionamento, Suarez e Bandeira (2002, p. 143) afirmam que a temática da violência é objeto de investigação atual e ocupa relevância no campo sociológico desde a década de 1970.

Contudo, as análises sociológicas acerca da violência majoritariamente, promovida pelo Estado, encobriam outras formas de violência ocorridas no cotidiano e nas relações interpessoais, envolvidas em uma hierarquia de poder, no geral, entre homens e mulheres com algum vínculo, mais comumente na esfera privada.

Almeida (2007, p. 27) explica o uso da expressão violência de gênero como mais utilizada pela academia nos estudos e pesquisas. Segundo a autora, a violência de gênero torna-se uma categoria que, além de potencializar a complexidade das relações sociais, em nível mais abstrato, consolidou-se como categoria analítica, remetendo aos lugares sociais sexuados, expondo as desigualdades às quais as mulheres estão submetidas e a ordem simbólica que envolve as relações sociais. 
Segato (2003, p.107-130) se manifesta sobre a violência moral, ocorrida em muitos casos de violência contra as mulheres e, para ela, a violência moral é uma ação que envolve agressão emocional, ainda que nãos seja consciente e deliberada.

De acordo com a autora, trata-se da argamassa para todos os outros tipos de violência de gênero, podendo ocorrer sem ofensa verbal explícita, por meio de gestos, atitudes ou olhares, uma vez que se inscreve no ambiente costumeiro.

A autora ainda cita como exemplos de violência moral, humilhação, intimidação, desqualificação, ridicularização, coação moral, suspeitas, desqualificação da sexualidade, desvalorização cotidiana da mulher como pessoa, de sua personalidade, de seu corpo, de suas capacidades cognitivas, de seu trabalho, de seu valor moral, dentre outras. Ressalta-se que a definição de violência moral trazida por Segato em muito se assemelha à definição de violência psicológica disposta na Lei Maria da Penha.

Contudo, colocar a mulher em uma posição vitimada e passiva não representa o real contexto dos episódios violentos, assim como afirma Gregori (1993, p. 143149), o vitimismo é o pior caminho tanto para compreensão do fenômeno quanto para o estímulo de transformações significativas nas relações entre os sexos. A autora considera importante na análise dos conflitos de violência contra as mulheres apreender as ambiguidades e tensões nas relações entre os papéis de gênero.

É preciso entender o contexto no qual a violência ocorre, e o significado que assume. Não cabe afirmar 'vai ver ela fez algo que o irritasse' no sentido de tornar justificável os atos de agressão. Este procedimento é o reverso da medalha na medida em que, mantendo a oposição agressor x vítima, desvitimiza para autorizar o uso da força. Mas, 'ela provocou e não evitou' e vale saber qual o sentido disso. Cabe indagar em que medida o entendimento desse sentido permite apreender essa situação, refeita cotidianamente, de manter a mulher dependente, submissa e exposta aos atos de agressão. (GREGORI, 1993, p. 149).

A partir do final dos anos 1970, como aduz Bandeira (2014, p.456), os assassinatos de mulheres cometidos pelos respectivos maridos, ex-maridos e companheiros ganharam visibilidade midiática e das autoridades, o que reforçou a mobilização da militância feminista nas demandas por políticas públicas de combate à violência contra as mulheres.

A autora explica que a correlação da violência com a condição de gênero teve sua origem inspirada nas questões e reivindicações do movimento feminista, a partir de evidências empíricas contundentes. A autora ressalta que desde o início dos anos 7o, as feministas americanas denunciavam a "violência sexual contra a mulher", porém, somente na década seguinte é que esse fenômeno passa a ser considerado categoria sociológica e área de pesquisa, configurando assim "violência contra a mulher", a qual se caracterizou como bandeira de luta central do movimento feminista brasileiro. 
Assim, as diversas ações acerca da violência contra as mulheres no Brasil, contribuíram para a politização deste tipo de violência e para cobrar respostas do Estado, que atendeu às demandas legal e formalmente, através de medidas de enfrentamento à violência contra a mulher, a citar como exemplos a criação das Delegacias Especializadas de Atendimento à Mulher (DEAMs) e da Lei no 11.340/2006, conhecida como Lei Maria da Penha, a qual visa à erradicação, coibição, punição e prevenção da violência doméstica e intrafamiliar.

Atualmente, mulheres ainda vivem em situação de violência e perdem suas vidas, não mais justificados oficialmente como crimes contra a honra, entretanto, agressores e assassinos por vezes justificam suas atitudes fundamentados na argumentação de que a mulher não está cumprindo seu papel de mãe, de dona de casa e de esposa por estar trabalhando fora, por estar se dedicando aos estudos ou envolvida em redes sociais. Elas também morrem porque dizem não, porque dançam, porque sorriem.

Em razão do número crescente de casos de violência contra a mulher, medidas de enfrentamento acerca do problema foram adotadas no campo das políticas públicas.

No ano de 2004, foi estruturada a Política Nacional de Enfrentamento à Violência contra as Mulheres, reformulada em 2011, a qual estabelece conceitos, princípios, diretrizes e ações de prevenção e combate à violência contra as mulheres, fundamentada na garantia dos direitos da mulher e na assistência a mulheres em situação de violência.

Buscando a melhoria no atendimento à mulher em situação de violência, em 2005, foi criada a Central de Atendimento à Mulher - Ligue 180. Esta importante medida presta auxílio às mulheres quanto aos seus direitos e a informações de locais onde possam obter ajuda, possui atendimento 24 horas por dia, sem intervalos, funcionando todos os dias de semana, incluindo fins de semana e feriados.

O Ligue 180 tem o objetivo de receber as denúncias de violência, reclamações sobre os serviços da rede de atendimento à mulher e de orientar as mulheres sobre seus direitos e sobre a legislação vigente, encaminhando-as para outros serviços, quando assim necessário.

$\mathrm{O}$ ano de 2006 marca a adoção de uma das mais importantes medidas do combate à violência contra as mulheres através da criação da Lei no. 11.340/2006, a Lei Maria da Penha. O referido ordenamento jurídico cria mecanismos para coibir e prevenir a violência contra a mulher, dispõe sobre a criação dos Juizados de Violência Doméstica e Familiar contra a Mulher, e estabelece medidas de assistência e proteção às mulheres em situação de violência doméstica e familiar.

Ademais, a Lei Maria da Penha promove o resgate das casas-abrigo para o acolhimento de mulheres (e seus filhos menores) em situação de violência que estejam em risco de vida, além de dispor sobre a articulação integrada dos serviços de atendimento às mulheres em situação de violência.

A SPM, no ano de 2007, lançou o Pacto Nacional pelo Enfrentamento à Violência contra as Mulheres, o qual consiste em um acordo federativo entre os 
governos federal, estaduais e municipais para o planejamento de ações que visem à consolidação da Política Nacional de Enfrentamento à Violência contra as Mulheres, através da implementação de políticas públicas integradas em todo país.

O Pacto foi atualizado em 2011 para atender melhor aos seus objetivos fundamentados, principalmente, em estabelecer e criar metas entre as esferas federal, estadual e municipal para prevenir e combater a violência contra as mulheres, em todas as suas formas, reforçando a aplicação da Lei Maria da Penha e a articulação entre os serviços de assistência social, saúde, segurança pública e justiça, além de prever o aumento do número de casas-abrigo e abrigamentos provisórios para garantia de vida de mulheres em risco de vida.

Destaca-se ainda, no ano de 2015, a criação da Lei no 13.104/2015, a chama Lei do Feminicídio, a qual classifica o feminicídio como crime hediondo e com agravantes quando o fato criminoso acontece em situações específicas de vulnerabilidade, como gravidez, no caso de menor de idade e na presença dos filhos. Por feminicídio, entende-se

(...) o assassinato de uma mulher pela condição de ser mulher. Suas motivações mais usuais são o ódio, o desprezo ou o sentimento de perda do controle e da propriedade sobre as mulheres, comuns em sociedades marcadas pela associação de papéis discriminatórios ao feminino. (Agência Patrícia Galvão, 2016).

O que mais chama a atenção nos crimes de feminicídio é o contexto íntimo e familiar da violência impetrada que se verifica na maioria dos casos e que vem acompanhado de outras formas de violência, anteriormente praticadas.

\section{Casas-abrigo: o abrigamento como garantia de vida}

As casas-abrigo fazem parte dos serviços especializados que compõem a rede de atendimento às mulheres em situação de violência, ao quais possuem a finalidade de fornecer, de forma temporária, medidas de caráter emergencial de proteção, acolhendo as mulheres e seus filhos menores.

Trata-se de locais seguros que, além de garantir a proteção, oferecem atendimento multidisciplinar a mulheres e filhos(as) em situação de risco de vida. $O$ serviço tem caráter temporário e sigiloso, onde as usuárias podem viver, por tempo determinado, com segurança até obter condições de prosseguir com suas vidas, afastadas dos episódios violentos.

Com a finalidade de traçar parâmetros para o atendimento e o funcionamento das casas-abrigo e formar um consenso de âmbito nacional, no ano de 2005, a SPM elaborou o Termo de Referência para Implantação e Implementação das CasasAbrigo, que conceitualmente define: 
Casas-Abrigo são locais seguros que oferecem abrigo protegido e atendimento integral às mulheres em situação de risco de vida iminente, em razão de violência doméstica. É um serviço de caráter sigiloso e temporário, onde as usuárias poderão permanecer por um período determinado, durante o qual deverão reunir condições necessárias para retomar o curso de suas vidas.

O atendimento deve pautar-se no questionamento das relações de gênero enquanto construção histórico-cultural das relações desiguais entre homens e mulheres, que legitimam e estão na base da violência contra as mulheres.

Segundo o Termo, o objetivo principal dos trabalhos desenvolvidos nas casasabrigo é garantir a integridade física e psicológica de mulheres em risco de vida e de seus filhos de menor idade - crianças e/ou adolescentes -, favorecendo o exercício de sua condição de cidadã.

$\mathrm{O}$ atendimento nas casas-abrigo deve se dar de forma integral, através de equipes capacitadas que realizem um trabalho coletivo, levando a repensar as relações afetivas violentas sob a perspectiva da desigualdade de gênero, com gestão participativa, a qual estabeleça uma rede de parcerias com outros serviços.

A implantação de casas-abrigo é restrita a municípios com mais de 50.000 habitantes e, quanto à sua localização, a unidade deve se situar, preferencialmente, em área residencial, sem guaritas aparentes ou qualquer tipo de identificação, em razão do sigilo.

Vale notar que a avaliação da gravidade dos casos de violência contra as mulheres é fundamental para o encaminhamento das situações de abrigamento e deve ser realizada por um serviço especializado no atendimento de mulheres em situação de violência, visto que o limite entre ameaça, risco de morte e risco iminente de morte é bastante tênue e varia de acordo com o tipo de violência sofrida.

Outro aspecto que merece ser ressaltado é a própria negação da mulher em relação à gravidade da violência sofrida. Desta forma, uma avaliação quanto à necessidade de abrigamento em diferentes casos (com ou sem risco de morte) requer não somente a escuta da fala da mulher, mas também a aplicação de instrumentos objetivos para mensurar os graus de risco da situação, como expresso nas Diretrizes.

A mulher que esteja em processo de desabrigamento deverá ser acompanhada pelo Centro de Referência mais próximo de sua residência. No caso de inexistência do serviço, o acompanhamento pós-abrigamento poderá ser realizado pelo CREAS, mediante prévia articulação e negociação no âmbito da rede de atendimento local.

No desabrigamento, é fundamental que a casa-abrigo e os Centros de Referência articulem estratégias conjuntas para garantir à mulher acesso à habitação, como auxílio aluguel, por exemplo, e ao trabalho, à inclusão em programas sociais e de geração de renda, etc. 
O abrigamento se apresenta como medida de caráter emergencial para garantia e proteção à vida de mulheres em situação de violência, contudo, muito ainda se questiona sobre a política de abrigamento no Brasil, como ressaltado por Prates e Alvarenga (2008, p. 17), quando consideram frágil o monitoramento das casas-abrigo, sua relação com o sigilo e se de fato o abrigo seria o modelo mais adequado para proteger as mulheres em risco de vida.

É isso que viemos questionar ao analisar o contexto prático do abrigamento, sob a perspectiva das usuárias.

\section{Casa-Abrigo Municipal de Campina Grande/PB - Casa da Mulher}

A Casa-Abrigo Municipal de Campina Grande/PB - Casa da Mulher (CAMCG) faz parte da rede municipal de atendimento às mulheres em situação de violência com o objetivo de garantir proteção às mulheres que correm risco de morte.

Com relação ao seu público-alvo, a CAMCG atende mulheres em situação de violência doméstica e familiar, sem limite de idade para as usuárias e seus filhos, com idade até 16 anos, os quais possuam residência no município de Campina Grande.

O procedimento inicial para o abrigamento deve obedecer ao encaminhamento pelo órgão demandante, em sua grande maioria, através da DEAM, cuja solicitação passará necessariamente pela Coordenadoria Especial de Políticas Públicas para as Mulheres, exceto nos fins de semana e feriados, onde o contato é feito diretamente com a coordenação da casa-abrigo.

Segundo informado pela assistente social e pela coordenadora da CAMCG, existe a necessidade da formalização do Boletim de Ocorrência para todos os casos de solicitação de abrigamento, realizado junto a DEAM, e mesmo quando as mulheres em situação de violência procuram atendimento através do Centro de Referência de Atendimento à Mulher, do CREAS ou qualquer outra porta de entrada, são encaminhadas para DEAM para que tenham sua ocorrência registrada.

É através do registro da ocorrência nas DEAMs que se pode iniciar os procedimentos investigatórios e, posteriormente, o processo judicial do agressor, enquadrado nas penalidades da Lei Maria da Penha.

Segundo informações da assistente social da unidade, nos últimos meses, diversas mulheres que, embora necessitassem do abrigamento para garantia de suas vidas, não aceitaram serem abrigadas, em razão de não poderem permanecer com o aparelho celular, durante o período do acolhimento.

A funcionária explicou que "Nós atendemos algumas mulheres recentemente, mas quando explicamos que o celular tem que ser confiscado e que não podem ter contato com ninguém, elas não quiseram ficar de jeito nenhum. Agora mesmo no mês de junho foi pior: elas não aceitaram ficar pra não perder a festa. Tinha umas que dizia 'e eu vou ficar presa e ele solto curtindo o São João?' E por isso quase não teve abrigamento em junho." 
Na oportunidade, a assistente social falou a respeito da necessidade de aceitação por parte das mulheres para que possam ser acolhidas na casa-abrigo. Sobre este aspecto, ela disse "Em nenhuma casa-abrigo as mulheres ficam obrigadas; é preciso que elas aceitem e isso faz parte da política de abrigamento. Elas assinam um termo aceitando ficar abrigadas e aceitando as regras de manter o sigilo e de entregar o celular. Isso tudo é medida de segurança, pra evitar que elas acabem contando onde fica a casa-abrigo.”

\section{A Casa Abrigo no Olhar das Abrigadas: Vantagens e Desvantagens}

A metodologia utilizada nessa pesquisa foi a entrevista semi estruturada com abrigadas, egressas da unidade, além da equipe técnica. Entrevistamos um total de 13 mulheres, entre elas 04 abrigadas e og egressas da unidade da CAMCG, com idades entre 18 e 57 anos. Para preservação da identidade das entrevistadas, optamos por utilizar nomes fictícios.

Os casos encontrados apresentam vários pontos em comum, apesar de suas peculiaridades.

As narrativas revelam que as agressões partiram, na grande maioria, dos maridos ou companheiros e em apenas dois casos, foram praticadas por namorados. Em ambos os casos, as jovens agredidas relataram o ciúme possessivo dos parceiros como motivação para a decisão de romper os relacionamentos e os episódios violentos se deram pela não aceitação do término da relação pelos agressores.

Rosa, estudante, de 20 anos, ferida no braço com uma faca, contou que seu então namorado "já tinha me empurrado e apertado meu braço algumas vezes; ele é ciumento e eu não queria mais continuar o namoro, quando fui terminar ele não aceitou; ele não era assim no início, mas com o tempo foi ficando ciumento a ponto de ter ciúme da minha família, dos meus irmãos, da minha mãe, das minhas irmãs, era complicado".

Situação semelhante foi relatada por Joana, 21 anos, estudante e funcionária em uma lanchonete, que contou que iniciou seu namoro na época da escola, mas o namorado começou a ter muito ciúme quando passaram a não estudar mais juntos: "ele implicava com tudo (...). Isso tudo foi me agoniando e eu quis acabar o namoro, ele ficou bem revoltado porque na cabeça dele era tudo normal demais, aí ele apertou meu braço, disse que não aceitava”.

Nos 13 casos analisados, foram verificadas todas as formas de violência, física, psicológica, moral, sexual e patrimonial. As entrevistas mostraram agressões físicas desde as mais "leves" até tentativas de homicídio com facas e sufocamento; violência psicológica na forma de ameaças; violência moral através de humilhações e ciúmes citados em alguns relatos; violência sexual impetrada no estupro conjugal e abusos sexuais; e violência patrimonial relatada por mulheres que tiverem seus pertences e documentos destruídos pelos seus agressores. 
No relato de Rita, 38 anos, a violência se mostra presente desde sua família de origem e quando foi indagada se sua família foi avisada da sua ida à casa-abrigo disse: "Minha mãe mora em Patos, mas não quis avisar a ninguém não. Não quis contar essas coisas, todo mundo acha normal, meu pai dava na minha mãe, meus irmão bate na mulher, nem adianta falar nada", onde observa-se claramente a naturalização e aceitação da violência.

A pesquisa observou importantes aspectos em relação à escalada das agressões, as quais em sua grande maioria seguiam em curva ascendente no tocante à intensidade em que a violência era empregada. Os depoimentos revelam o crescimento da intensidade dos episódios de violência, a qual se inicia, muitas vezes, com palavras grosseiras, passando para agressões verbais, gritos, empurrões, apertos no braço, tapas, murros, chutes, queimaduras, enforcamento e facadas.

Apenas em um dos relatos, o primeiro episódio violento se apresentou na forma de agressão física. Helena, 29 anos, contou que “(...) ele nunca foi agressivo, mas no dia do Natal, a gente fez a ceia em casa e tinha muita gente, gente que eu nem conhecia, aí do nada ele ficou louco, me puxou pelos cabelos (...), de repente ele puxa a faca".

As entrevistas também trouxeram o uso de bebidas alcoólicas como fatores desencadeantes do comportamento violento dos parceiros. Em 6 casos os episódios violentos estão sempre associados ao uso de álcool. A cabeleireira Patrícia, 42 anos, afirmou que "Quando ele bebia era um inferno, ele quebrava as coisas de casa e teve uma vez que ele queimou todas as minhas roupas, dizendo que não era roupa de mulher direita; já fez barraco no meu salão”.

No mesmo sentido, em um número igual de casos, as entrevistadas citaram o ciúme como outro elemento desencadeador, travestidos em justificativas, das agressões sofridas. No caso da atendente de farmácia, Susana, 30 anos, é afirmado que os dois elementos ocasionaram as agressões: “(...) toda vez que ele bebia, ele tava ficando alterado, agressivo. (...) dessa vez a gente tava numa boa, fazendo almoço, conversando e a gente brigou por conta de ciúme, meu e dele, aí eu fiquei com raiva e fui pra casa de uma amiga (...). Quando eu cheguei em casa ele não tava, chegou um tempo depois, batendo a porta e eu vi que ele tava bêbado (...)”.

Nos relatos das participantes entrevistadas, o medo de morrer é o principal motivador do rompimento do silêncio e a busca por ajuda, mesmo para aquelas que passaram suas vidas cercadas pela violência, seja de seus parceiros seja da família de origem, como no caso de Rita.

Em dois depoimentos, a posição dos filhos, os quais agiram em apoio e até mesmo conduzindo a mãe até a DEAM foram determinantes para formalização da ocorrência, como nos casos de Maria, 46 anos e de Luzia, 57 anos.

Em conversa com Maria, constantemente agredida por um marido violento, ela revelou "Meus filhos que me encorajaram a ir na delegacia; eles não aguentavam mais me ver apanhando e passando por essa humilhação”. Já Luzia, contou “(...) meus filhos cresceram, tudo já tem sua vida e suas casa, mas eles tava sempre preocupado comigo por causa dessas coisa do pai. Aí da vez que fui pro abrigo, ele chegou bêbado 
dizendo que ia me matar, aí eu liguei pra minha filha e ela foi me pegar, aí ele disse que ia matar nós duas, aí foi quando ela me levou na Delegacia da Mulher pra dar parte dele”.

O caso da estudante Madalena, 18 anos, é o mais peculiar de todas as entrevistas realizadas. O agressor não era seu marido, companheiro ou namorado, mas sim, seu padrasto, por quem era agredida e abusada sexualmente desde os 14 anos de idade.

A jovem relatou que temia sua vida uma vez que seu padrasto era um homem perigoso, líder de um grupo criminoso e procurado pela justiça. Era constantemente ameaçada de morte e sofria com os abusos, agressões e com o ciúme do agressor, chegando a viver em cárcere privado, abandonando seus estudos e sua vida social. Ela contou que "Quando fiz 18 anos fui na Delegacia pra contar o que acontecia comigo. Desde os meus 14 anos que sofro na mão do marido da minha mãe; ele me ameaçava e eu não tinha coragem e morria de vergonha, mas não aguentava mais não”.

Seu acolhimento se deu pelo risco iminente de morte e de não ter, no exato momento de sua saída de casa, nenhum outro local seguro que oferecesse proteção e segurança. Em um momento posterior, a equipe da CAMCG entrou em contato com parentes que se disponibilizaram a recebê-la. Atualmente, Madalena mora com seu pai em outra cidade.

O acolhimento de Madalena demonstra a abrangência do serviço oferecido pelas casas-abrigo que é estendido às vítimas de violência sexual que estejam em risco de morte, visando garantir a proteção de suas vidas.

Outro ponto em comum nos 13 casos analisados é o desconhecimento da existência da casa-abrigo e da rede de proteção às mulheres em situação de violência doméstica. Os únicos órgãos que compõem a rede que são de conhecimento geral são a DEAM e, em alguns (poucos) relatos, o Centro de Referência, e as entrevistadas afirmaram que só passaram a ter conhecimento da unidade quando estiveram nestes órgãos.

Na aceitação do acolhimento, o papel das famílias das abrigadas e egressas é fundamental, figurando como algumas razões pelas quais as fizeram aceitar e optar pelo abrigamento, por questões de segurança.

Durante as conversas, foi fácil perceber que as famílias podem não oferecer a proteção necessária, muitas vezes considerando normal a presença de violência nas relações; ainda a família pode não representar um local seguro, de fácil acesso pelo agressor, como na casa dos pais ou dos filhos; e em outros casos, a família não existe ou mora longe, o que torna a casa-abrigo a única opção realmente segura.

Para as participantes entrevistadas, o abrigamento cumpre seu objetivo de proteção, garantindo a segurança das mulheres que correm risco de vida, criando e estimulando alternativas para o seu empoderamento. Segundo o relato de Patrícia, “(...) seguro, tem policial, tem sempre gente, o endereço é sigiloso, aqui é seguro mesmo e a gente sente segurança. Então se pensar assim, a gente vê vantagem".

Para Luciana, 40 anos, "A casa-abrigo foi um refúgio, foi um apoio, foi uma segurança, foi uma saída, foi uma busca pelo órgão que é necessário pra gente ter essa punição (...)". 
Acerca de sua experiência na unidade, Rita contou que "A gente vai pra lá quando não tem pra onde ir e quando corre risco de vida, fora isso, o pessoal é muito humano, muito coração, ajuda, orienta (...)”.

Os depoimentos ainda ressaltam o trabalho desenvolvido pelas profissionais que compõem a equipe técnica da CAMCG, salientando o esforço para reinserção social das abrigadas para que, ao deixarem a casa-abrigo, as mulheres possam ter trabalho, moradia e/ou benefícios sociais concedidos. Um exemplo disso é o relato de Maria: "Tirei meus documentos com a ajuda delas, resolveram tudo do bolsa família, inscrição no CRAS, meu divórcio saiu com a ajuda da doutora de lá, recebo uma pensãozinha. Sem elas eu não conseguiria nada; você sabe que tudo é difícil, ainda mais pra mim que só escrevo meu nome e sei os número, mas já me matriculei, vou estudar (...)".

O relato da técnica em enfermagem, Cristina, 29 anos, confirma o posicionamento: "Elas foram ótimas, conversam, orientam, ajudam muito, fazem o que é preciso pra ajudar. O trabalho delas é bem importante eu acho”.

Contudo, em contrapartida, representa a sensação de prisão da pessoa errada e injustiça, uma vez que ficam impedidas de manter qualquer contato com qualquer pessoa, que não seja alguma das profissionais.

Na conversa com Patrícia, ficou claro seu incômodo com tal sensação quando ela afirmou "Eu tenho meu trabalho, meu salão, não posso ficar presa aqui (...) $O$ problema é que tem que ficar aqui enquanto ele não é preso, ai eu to aqui sem poder sair e ele tá solto. Eu penso que o ideal era que ele fosse logo preso pra eu poder voltar lá pra fora, mas Deus sabe, né?".

No mesmo sentido, Susana disse "Quero sair daqui. Ele é quem tem ser preso e não eu".

Além da sensação de prisão injusta, o fato de estarem sem os aparelhos celulares, regra geral das casas-abrigo por questões de segurança, representa um fator marcante o qual reforça o "aprisionamento".

Sobre esta questão, Luciana salientou “(...) a regra da casa-abrigo é você chegar, ela confiscar ter celular e você não tem contato com ninguém, então a sensação é muita injustiça porque quem te ameaçou, quem queria te bater está lá fora e você simplesmente está literalmente presa”.

Para Antônia, 34 anos, "O abrigo é bom, mas dá agonia ficar presa. (...) A gente fica sem comunicação com o mundo. (...) É horrível ficar sem contato com o mundo, porque elas toma logo seu celular, você tem que entregar, você não pode ter contato com ninguém, ninguém; é complicado. É quase uma sensação de você tá presa, sabe? Mas depois você vê que foi bom, que é pra sua proteção. A gente se sente protegida, mas é difícil”.

A técnica em enfermagem, Cristina, tem opinião semelhante: "Eu confesso que quase não aceito [ficar abrigada] porque tem que entregar o celular, mas eu tive medo de ir pra casa e meu marido ter outro ataque e me matar ou matar meu filho (...) ficar sem o celular, ficar incomunicável, não pode falar com ninguém (...). É injusto porque você tem que sair de casa pra não morrer; a mulher é agredida, fica correndo risco 
porque tem um monte de homem doido por aí e é ela quem tem que 'sair de circulação' [faz sinal de aspas] até a juíza dar a medida protetiva ou ele ser preso e você poder voltar pra casa”.

Rita também se mostrou incomodada e disse “(...) é ruim ficar sem o telefone, mas não tinha jeito, é regra da casa-abrigo e tem que manter a segurança do lugar; dá raiva porque você apanha e tem que ir pra casa-abrigo, mas depois você entende, as meninas vão explicando, é pro bem".

\section{Considerações finais}

No presente estudo, procurou-se situar a violência contra a mulher como fenômeno histórico, socialmente construído e, por esta razão, não natural, e que representa um grave problema social, jurídico, cultural e de saúde pública.

Assim, para tecer as considerações finais desta pesquisa, destacam-se aspectos importantes na análise dos dados coletados, bem como algumas reflexões em torno dos mesmos.

O primeiro aspecto a ser destacado é violência presente em todas as suas formas (física, psicológica, moral, sexual e patrimonial, como analisaremos adiante), percebida de maneira brutal e gratuita na vida das mulheres entrevistadas. Atentase para a violência que as fazem romper o silêncio e buscar ajuda, empregada de forma persistente durante o relacionamento. Alguns relatos apontam a presença da violência desde a família de origem e, nesta perspectiva, vislumbra-se a naturalização do fenômeno e, a partir disso, se inicia o processo de aceitação da violência.

Outro aspecto observado diz respeito à intensidade da violência e aos fatores que desencadeiam o comportamento violento dos agressores. Os depoimentos revelam o crescimento da intensidade dos episódios de violência, a qual se inicia, muitas vezes, com palavras grosseiras, passando para agressões verbais, empurrões, apertos no braço, tapas, murros, chutes, queimaduras, enforcamento e facadas.

Com relação aos fatores que desencadeiam o comportamento violento dos parceiros, evidencia-se as relações de poder contidas no descontrole do homem fundamentado no ciúme, desconfiança, uso de álcool, reação negativa ao pedido de divórcio ou fim da relação e, porque não dizer, na naturalização da violência que acarretam sua perpetração. Tais fatores, utilizados nos relatos das entrevistadas como justificativas para as agressões, representam desculpas para as práticas violentas e sua consequente naturalização.

Um ponto importante a ser destacado é em relação ao momento da decisão de romper o ciclo de violência. Nos relatos das participantes entrevistadas, percebe-se o medo de morrer como o principal ingrediente motivador das denúncias, mesmo para aquelas que passaram suas vidas cercadas pela violência, seja de seus parceiros seja da família de origem. Alguns depoimentos salientaram a posição dos filhos, os quais agiram em apoio e até mesmo conduzindo a mãe até a DEAM para formalização da 
ocorrência. Observa-se, na maioria das falas, a aceitação dos episódios violentos físicos, psicológicos, morais, sexuais, patrimoniais - que somente foram expostos e revelados pelo temor por suas vidas.

Outro aspecto que merece destaque refere-se aos tipos de violência contidos nos relatos das participantes. Através da análise dos depoimentos, constata-se que, além da violência física, mais perceptível e o tipo de violência que promove a busca por ajuda, encontra-se a presença constante da violência psicológica, principalmente atribuída à ameaça de morte. Entretanto, existe a presença dos outros tipos de violência em alguns relatos, como o reconhecimento da violência sexual, assim identificado pelas mulheres pelo fato de serem forçadas a manter relação sexual com o parceiro. Por sua vez, a violência moral é apresentada algumas vezes nos depoimentos quando as entrevistadas são tratadas pelos parceiros com menosprezo, desdém ou como incapazes, além de se submeterem a humilhações. Ainda, pode-se verificar relatos contendo casos de violência patrimonial, através da destruição de documentos e roupas realizados pelo agressor como uma maneira cruel de desidentificação dessas mulheres.

No que diz respeito ao papel das famílias das abrigadas e egressas no processo do abrigamento, observa-se, em seus depoimentos, algumas razões pelas quais as fizeram optar pela casa-abrigo, como forma de segurança. Em alguns relatos, constatase que a família não oferece proteção, quando não se envolve ou considera normal a presença de violência nos relacionamentos; ainda a família pode não representar um local seguro, de fácil acesso pelo agressor, como na casa dos pais ou dos filhos. Em outros casos, a família não existe ou mora longe, o que torna a casa-abrigo a única opção segura.

O histórico de violência vivenciado por estas mulheres deixam, sem dúvidas, consequências emocionais, além das marcas visíveis, oriundas das agressões físicas. Contudo, a violência física vem acompanhada de uma violência psicológica, que pode trazer danos ainda mais graves. Entre os danos psicológicos e emocionais verificados nos depoimentos das participantes, pode-se perceber ansiedade, vergonha, humilhação e medo, este aliás, muito citado nos relatos.

Passando para a análise do funcionamento das casas-abrigo, com relação ao trabalho desenvolvido pelas profissionais que compõem a equipe técnica da casaabrigo objeto deste estudo, observa-se nos depoimentos que o suporte oferecido pelas funcionárias possibilita que as mulheres reflitam sobre suas vidas e as ajuda a encontrar meios de lidar com o problema da violência. Dentre as ações informadas pelas profissionais das equipes e relatadas pelas mulheres entrevistadas, a reinserção social das abrigadas é reconhecida como esforço conjunto para que, ao deixarem a casa-abrigo, as mulheres possam ter trabalho, moradia e/ou benefícios sociais concedidos.

A partir dos relatos das participantes entrevistadas é possível verificar um dos aspectos mais importantes constatados pela presente pesquisa. No tocante à política de abrigamento, observa-se a presença constante, nas falas das mulheres entrevistadas, do questionamento (implícito ou explícito) acerca de se sentirem 
presas e o consequente incômodo por seus agressores permanecerem soltos, o que se exprime como uma inversão injusta. Tal fato pode ser percebido também nos relatos das funcionárias da unidade analisada.

Neste sentido, pode-se estabelecer um paralelo entre as casas-abrigo e o conceito de instituição total, elaborado por Goffman ${ }^{1}(1987$, p. 16) quando o autor explica que se caracteriza pelo seu "fechamento" mediante barreiras levantadas para segregar os internados do contato social com o mundo exterior.

Goffman defende que as instituições totais estão divididas em cinco agrupamento ou categorias: a) as criadas para cuidar de pessoas que são consideradas incapazes e inofensivas, tais como as casas de cegos, asilos para idosos e órfãos e indigentes; b) locais estabelecidos para cuidar de pessoas consideradas incapazes de cuidar de si mesmas eque são também uma ameaça não intencional para a comunidade, como sanatórios para tuberculosos, hospitais para doentes mentais e leprosários; c) as criadas para proteger a comunidade contra as ameaças e perigos intencionais, sem se importar muito com o bem-estar das pessoas segregadas, como as cadeias, os penitenciárias, campos de prisioneiros de guerra e campos de concentração; d) as estabelecidas com a intenção de realizar de um modo mais adequado alguma tarefa de trabalho, como quartéis navios, escolas internas, campos de trabalho, colônias; e) os estabelecimentos destinados a servir de refúgio do mundo, que também podem servir como locais de instrução para religiosos, como abadias, mosteiros, conventos e outros claustros.

Assim, as casas-abrigo se assemelham, dentro das cinco categorias elencadas por Goffman, nas instituições totais criadas para cuidar de pessoas que são consideradas incapazes e inofensivas, tendo em vista que as ameaças e perigos intencionais estão do lado de fora.

Cite-se, ainda, o controle e a vigilância sobre os internados, sob a responsabilidade de um grupo dirigente, os quais cobram o cumprimento das normas estabelecidas pela instituição.

No abrigamento, a barreira com o mundo exterior, argumentado por Goffman, se concretiza, principalmente, pela retenção do aparelho celular das abrigadas como regra da unidade, tão logo aceitem seu ingresso.

O autor também se refere ao objetivo das instituições totais que podem ser: realização de algum objetivo econômico, educacional, instrução, tratamento médico ou psiquiátrico, purificação religiosa e proteção da comunidade mais ampla.

No tocante às casas-abrigo, destacam-se seus objetivos de proteção, segurança e garantia de vida das mulheres abrigadas, além do caráter instrutivo em relação às normas e à toda rede que as protegem.

Contudo, como demonstram vários estudos sobre moradores de rua, há resistência da parte deles, mesmo nas noites mais frias, em aceitar o acolhimento

1 Erving Goffman (1987, p. 22) define a instituição total como "um local de residência e de trabalho onde um grande número de indivíduos com situação semelhante, separados da sociedade mais ampla por um período considerável de tempo, levam uma vida fechada e formalmente administrada." GOFFMAN, Erving. Manicômios, prisões e conventos. 2ª Edição. São Paulo: Editora Perspectiva. 1987. 
nos albergues, justamente devido às restrições impostas que consideram excesso de regras. Uma das mais conhecidas é a proibição de levar animais para os albergues.

Para as participantes entrevistadas, o abrigamento cumpre seu objetivo de proteção, garantindo a segurança das mulheres que correm risco de vida, criando e estimulando alternativas para o seu empoderamento, porém, em contrapartida, representa a sensação de prisão da pessoa errada e injustiça, uma vez que ficam impedidas de manter qualquer contato com qualquer pessoa, que não seja alguma das profissionais.

No que se refere ao suporte pós-abrigamento, entende-se ser de fundamental importância que haja um acompanhamento pós-abrigamento das mulheres para que se possa avaliar a efetividades das ações educativas realizadas na casa-abrigo. Verificando o suporte pós-abrigamento oferecido pelas casas-abrigo em análise, defende-se o posicionamento de que, para que as políticas públicas de enfrentamento à violência contra a mulher sejam plenamente eficazes, é necessário percebê-lo como parte de todo o sistema de acolhimento.

Diante dos apontamentos aqui tecidos, evidencia-se que esta pesquisa trouxe resultados relevantes para a produção do conhecimento em torno da temática estudada. Assim, nesse sentido, novas pesquisas podem ser realizadas, a citar como sugestão estudos com os filhos de mulheres que passaram pela casa-abrigo e que também lá estiveram abrigados, no intuito de analisar a efetividade do local em termos de prevenção e o impacto da violência nas histórias de vida dos filhos. Igualmente, entende-se ser importante analisar a eficácia das medidas de segurança concedidas para averiguar até que ponto elas são realmente seguras e podem garantir a segurança das mulheres em situação de violência que denunciaram seus agressores.

\section{Referências bibliográficas}

AGÊNCIA PATRÍCIA GALVÃO. Feminicídio. 2016. Disponível em: http://www. agenciapatriciagalvao.org.br/dossie/violencias/feminicidio/. Acesso em: 29/o4/2017.

ALMEIDA, Suely Souza de. "Essa violência mal-dita". In: ALMEIDA, Suely Souza de (Org.). Violência de gênero e políticas públicas. Rio de Janeiro: Ed. da UFRJ, 2007. Disponível em: http://www.scielo.br/scielo.php?script=sci_ nlinks\&ref=000199\&pid=So102-6992200900020000400001\&lng=pt. Acesso em: o8/10/2015.

AMORIM, Elba Ravane Alves; BARROS, Ana Maria. A casa abrigo para mulheres vítimas de violência doméstica e os direitos humanos. 2014. Disponível em: http:// www.encontro2014.andhep.org.br/resources/anais/1/1398295795_ARQUIVO_ACASAABRIGOPARAMULHERESVITIMASDEVIOLENCIADOMESTICAEOSDIREITOSHUMANOS.pdf. Acesso em: 29/o7/2015. 
BANDEIRA, Lourdes Maria; ALMEIDA, Tania Mara Campos de. "Vinte anos da Convenção de Belém do Pará ea Lei Maria da Penha”. Florianópolis: Estudos Feministas, 2015. Disponível em: http://www.scielo.br/pdf/ref/v23n2/0104-026X-ref-23-02-00501. pdf. Acesso em: 07/10/2015.

Lourdes Maria. "Violência de gênero: a construção de um campo teórico e de investigação". Sociedade e estado, Brasília, v. 29, n. 2, p. 449-469, 2014. Disponível em: <http://www.scielo.br/scielo.php?script=sci_arttext\&pid=So102$69922014000200008 \& \operatorname{lng}=\mathrm{en} \& \mathrm{nrm}=\mathrm{iso}>$. Acesso em: 18/04/2017.

BRASIL. Presidência da República. Lei no. 11.340, de 7 de agosto de 2006. (Lei Maria da Penha). Disponível em: http://www.planalto.gov.br/ccivil_03/_ato2004-2006/2006/ lei/l11340.htm. Acesso em: 02/o7/2015.

Presidência da República. Secretaria Especial de Políticas para mulheres. Política Nacional de Enfrentamento à Violência contra as Mulheres. Brasília: Secretaria Especial de Políticas para Mulheres, 2011. Disponível em: http://www.spm.gov.br/ sobre/publicacoes/publicacoes/2011/politica-nacional. Acesso em: 15/o9/2015.

Presidência da República. Secretaria Especial de Políticas para mulheres. Pacto Nacional pelo Enfrentamento à Violência contra as Mulheres. Brasília: Secretaria Especial de Políticas para Mulheres, 2011. Disponível em: http://www.spm.gov.br/ sobre/publicacoes/publicacoes/2011/pacto-nacional. Acesso em: 15/og/2015.

Presidência da República. Secretaria Especial de Políticas para mulheres. Rede de Enfrentamento à Violência contra as Mulheres. Brasília: Secretaria Especial de Políticas para Mulheres, 2011. Disponível em: http://www.spm.gov.br/sobre/ publicacoes/publicacoes/2011/rede-de-enfrentamento/view. Acesso em: 15/og/2015.

Presidência da República. Secretaria Especial de Políticas para mulheres. Termo de Referência para Implantação e Implementação de Casas-Abrigo. Brasília: Secretaria Especial de Políticas para Mulheres, 2005 Disponível em: http://www. spm.gov.br/arquivos-diversos/.arquivos/tr_cs_abrigo_2005_integra. Acesso em: $17 / 10 / 2015$.

Presidência da República. Secretaria Especial de Políticas para mulheres. Diretrizes Nacionais para o Abrigamento. Brasília: Secretaria Especial de Políticas para Mulheres, 2011. Disponível em: http://www.spm.gov.br/sobre/publicacoes/ publicacoes/2011/abrigamento. Acesso em: 15/09/2015. 
Presidência da República. Secretaria Especial de Políticas para mulheres. Ligue 18o Balanço 2015. Brasília: Secretaria Especial de Políticas para Mulheres, 2016. Disponível em: http://www.spm.gov.br/assuntos/violencia/ligue-18o-central-deatendimento-a-mulher/balanco18o-2015.pdf. Acesso em: 02/02/2017.

Presidência da República. Portal Brasil. Aumento de serviços tem ajudado no combate à violência contra a mulher. Brasília: Portal Brasil, 2014. Disponível em: http://www.brasil.gov.br/cidadania-e-justica/2014/o8/Aumento-de-servicos-temajudado-no-combate-a-violencia-contra-a-mulher. Acesso em: 27/o2/2016.

CARNEIRO, Alcides; OLIVEIRA, Soraya. Violência intrafamiliar baseada em gênero com implicação de risco de vida: mulheres abrigadas na Casa Abrigo Maria Haydeé / Rio Mulher / Rio de Janeiro. 20o8. Disponível em: http://www.abep.nepo.unicamp. br/encontro20o8/docsPDF/ABEP2008_1031.pdf. Acesso em: 07/10/2015.

GOFFMAN, Erving. Manicômios, Prisões e Conventos. 2ª Edição. São Paulo: Editora Perspectiva, 1987.

GREGORI, Maria Filomena. Cenas e queixas: um estudo sobre mulheres, relações violentas e a prática feminista. Rio de janeiro: Paz e Terra; São Paulo: Anpocs, 1993.

- Maria Filomena. "As desventuras do vitimismo". Estudos Feministas, Rio de Janeiro, v. 1, p. 143-150, 1993. Disponível em: http://www.scielo.br/scielo. php?script=sci_nlinks\&ref=oo0102\&pid=S0103-7331200600020000300011\&lng=pt. Acesso em: 31/o7/2017.

ORGANIZAÇÃO MUNDIAL DE SAÚDE - OMS. Relatório mundial sobre violência e saúde. Genebra: Organização Mundial de Saúde, 2002.

PRATES, Paula Licursi; ALVARENGA, Augusta Thereza de. "Perfil Sociodemografico e psicossocial de mulheres abrigadas, em situação de violência”. In: XVI Encontro Nacional de Estudos Populacionas-ABEP 2008, Caxambu/MG, 2008.

SILVEIRA, Lenira Politano da. "Serviços de Atendimento a mulheres vítimas de violência”. In: DINIZ, Simone, SILVEIRA, Lenira e MIRIM, Liz (org.). Vinte e cinco anos de respostas brasileiras em violência contra a mulher (1980-2005) - alcances e limites. São Paulo: Coletivo Feminista Sexualidade e Saúde, 2006.

SEGATO, Rita Laura. Las estructuras elementales de la violência - ensayos sobre gênero entre antropologia, psicoanálisis y derechos humanos. Buenos Aires: Prometeo, 2003. Disponível em: http://www.escuelamagistratura.gov.ar/images/uploads/estructura vg-rita_segato.pdf. Acesso em: 18/o4/2017. 
SUAREZ, Mireya; BANDEIRA, Lourdes. "A politização da violência contra a mulher e o fortalecimento da cidadania". In: BRUSCHINI, Cristina; UNBEHAUM, Sandra (Orgs.). Gênero, democracia e sociedade brasileira. São Paulo: Editora 34; Carlos Chagas, 2002. 